\title{
Simplified Probabilistic Model for Maximum Traffic Load from Weigh-In-Motion Data
}

M. Soriano ${ }^{1}$, J.R. Casas ${ }^{1, *}$ and M. Ghosn ${ }^{2}$

${ }^{I}$ School of Civil Engineering, Technical University of Catalonia-BarcelonaTech, Barcelona, Spain

${ }^{2}$ Department of Civil Engineering, The City College of New York/CUNY, New York, USA

*corresponding author: joan.ramon.casas@upc.edu 


\title{
Simplified Probabilistic Model for Maximum Traffic Load from Weigh-In-Motion Data
}

\author{
This paper reviews the simplified procedure proposed by Ghosn and Sivakumar \\ to model the maximum expected traffic load effect on highway bridges and \\ illustrates the methodology using a set of Weigh-In-Motion (WIM) data collected \\ on one site in the U.S. The paper compares different approaches for \\ implementing the procedure and explores the effects of limitations in the site- \\ specific data on the projected maximum live load effect for different bridge \\ service lives. A sensitivity analysis is carried out on the most representative \\ variables involved in the WIM data collection and calculation of the maximum \\ load effect. The procedure is implemented on a set of WIM data collected in \\ Slovenia to study the maximum load effect on existing Slovenian highway \\ bridges and how it compares with the values obtained from the Eurocode of \\ actions.
}

Keywords: weigh-in-motion, bridge, traffic load, extrapolation

\section{Introduction}

Over the last two decades, highway agencies have recognized the importance of having automated data collection systems that can provide information on truck weights and truck traffic patterns for economic analysis, traffic management and various other purposes. To meet that goal, various types of Weigh-In-Motion systems have been widely deployed to collect large quantities of unbiased truck data at normal highway speeds in an undetected manner to avoid truck driver's knowledge. Weigh-in-motion (WIM) equipment currently in use can collect data on truck volumes, axle configurations, axle weights, truck arrival times and load spectra. These WIM systems are based on different technologies with varying performance and cost considerations. Piezoelectric sensor-based systems offer acceptable accuracy (usually $\pm 15 \%$ for gross weights) at such low cost that their use has become quite widespread (NCHRP 2011). Although primarily used for traffic management purposes, WIM data have also been used to develop new live load models and assess current bridge designs and bridge ratings (Moses et al. 
1984, Ghosn and Moses 1986, Ghosn et al. 1986, Frangopol et al. 1992, O’Brien and Znidaric 2001, Crespo and Casas 1997, Nowak and Nassif 1992, Nowak 1999, Casas and Gómez 2013). Wisniewski et al. (2013) propose the use of WIM data as one of the key factors in the actual development of codes for advanced bridge assessment. The use of WIM data for bridge evaluation requires a careful evaluation of the quantity and quality of available data. For example, a study by Laman and Nowak (1997) shows that truck loads are strongly site specific and depend on traffic volume, local industry, and law enforcement effort. A negative correlation was found between law enforcement effort and the occurrence of overloaded trucks. Truck load growth trends have been assessed utilizing WIM data. For instance, a large-scale California study has established that truck volumes have increased over time even though gross vehicle weight spectra in the state have remained largely unchanged. That study also investigated the possibility of applying WIM data collected at a given bridge site to other nearby bridge locations (Lu et al 2002). Ghosn and Frangopol (1996) focused on the use of WIM data to define site-specific bridge loads, and highlighted the differences in estimated safety levels that result from applying site-specific values for bridge evaluation rather than national average load data. Several studies used WIM traffic data to demonstrate how current code-specified load models could provide non-conservative estimates of actual loads experienced by some bridges (ARCHES-D08, Enright and O’Brien 2013). Conversely, in other cases, WIM data revealed that many bridges are designed for traffic live-loads that they will never experience during their expected service-life (Casas 1999 ). This fact is of relevant importance when facing the safety assessment of existing bridges.

The examination of truck multiple presence on bridges has employed WIM data to simulate multi-lane traffic critical loading events and extreme load effects. It was generally noted that as the span length increases, the critical loading event is governed by an increasing number of trucks (Caprani et al. 2002). One study indicated that traffic density should be a deciding factor in the development of multiple presence reduction factors (Gindy and Nassif 2006 ). 
WIM data has also been applied to the development of new fatigue models and the assessment of existing models (Crespo and Casas 1998, Casas 2000). Cyclic fatigue investigations reveal that fatigue load spectra are highly site specific and that code specified load models often misrepresented actual fatigue damage even after accounting for the safety factors (Moses et al. 1987, Grundy and Boully 2004, Wang et al. 2005, Cohen et al. 2003, Laman and Nowak 1996).

As shown, WIM data have many applications in bridge engineering. One important application is projecting the data to estimate the maximum traffic actions that bridges may be subjected to within a reference period. Several methods have been proposed to this end (Treacy et al. 2014, O’Brien et al. 2015). However, most of these are based on complicated and cumbersome simulation processes that require excessive computational effort and specialized expertise making them difficult to implement in everyday engineering practice when evaluating the safety of specific bridges. This paper illustrates the implementation of variations on a simplified procedure developed by Ghosn and Sivakumar (Ghosn and Sivakumar 2010, NCHRP 2011) to estimate the maximum expected load effect on a highway bridge. The procedure explains how sitespecific Weigh-In-Motion (WIM) truck weight and traffic data can be used to obtain estimates of the maximum live load for the service life of a bridge using an easily implementable simple technique. The application of the procedure is described using data collected at a WIM site in New York State. A sensitivity analysis is performed to identify the most critical parameters that control the projection of the expected maximum load and to study the effect of limitations in the WIM database. The validity of the procedure is verified by implementing it on a set of WIM data collected in Slovenia that had been previously analyzed using more complex methods (ARCHES D08, Enright and O`Brien 2013). 


\section{Analysis of maximum load effect}

Bridges must safely support the maximum traffic load expected within their service lives. This maximum load may be due to the crossing over the bridge of a single heavy truck or a number of trucks simultaneously. The governing load depends on the axle spacing and weights of the trucks that cross in each lane of the bridge and the probability of simultaneous truck crossings. The probability of simultaneous crossings depends on the traffic characteristics including headway spacing and bridge length. Ideally, such data should be available for an entire period equal to the service life of the bridge. However, despite the recent proliferation of WIM systems, collecting the necessary data to obtain the maximum load is not possible because decisions on the safety of the bridge should be made before exposing it to the most hazardous loads and because short term data may not actually contain the worst possible loading scenarios. Also, data previously collected on one site may not necessarily represent future loads at the same or at different sites. For these reasons, the safety assessment of bridges must be performed using probabilistic methods based on a statistical projection of the maximum expected load from a set of data collected over a relatively short period of time.

The load effect of each truck on a particular bridge can be obtained by passing the truck through the appropriate influence line. Of particular importance for bridge designers and evaluators are the moment and shear effects at critical cross sections. The maximum loads on short to medium span bridges are governed by moving trucks rather than congested truck conditions (Nowak, 1999, Caprani et al 2002). Because of the nature of truck traffic as well as the moment and shear influence lines of short to medium span bridges, the maximum load on multi-lane bridges with spans less than 60 $\mathrm{m}$ is governed by a single heavy truck, two side-by-side or for continuous spans, two 
trucks following in the same lane. These observations render the modeling of the maximum load effects easy to implement using basic concepts of probability theory. In that vein, the ensemble of the load effects for each truck can be assembled into a histogram where each bin associated with a load effect $x_{i}$, gives the percentage of the load effects ranging between $\mathrm{x}_{\mathrm{li}}$ and $\mathrm{x}_{\mathrm{ui}}$. The histogram value in each bin $\mathrm{H}\left(\mathrm{x}_{\mathrm{i}}\right)$ would be related to the probability distribution of the truck effect $\mathrm{f}_{\mathrm{x}}(\mathrm{x})$ by:

$$
H\left(x_{i}\right)=\int_{X_{l i}}^{X_{u i}} f_{x}(x) d x
$$

The total load effect when two side-by-side (or following) trucks are on a bridge is obtained from $\mathrm{x}_{\mathrm{S}}=\mathrm{x}_{1}+\mathrm{x}_{2}$ where $\mathrm{x}_{1}$ is the effect of the main truck and $\mathrm{x}_{2}$ is the effect of the second truck.

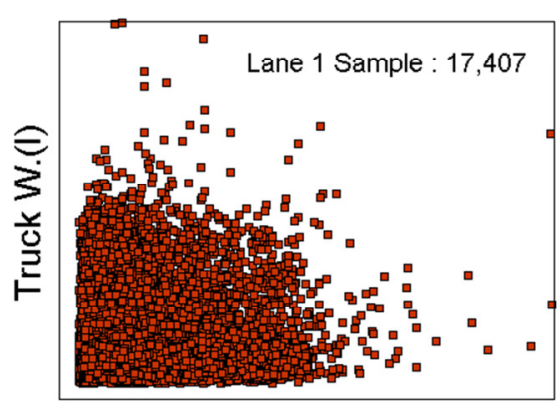

Truck W.(1+1)

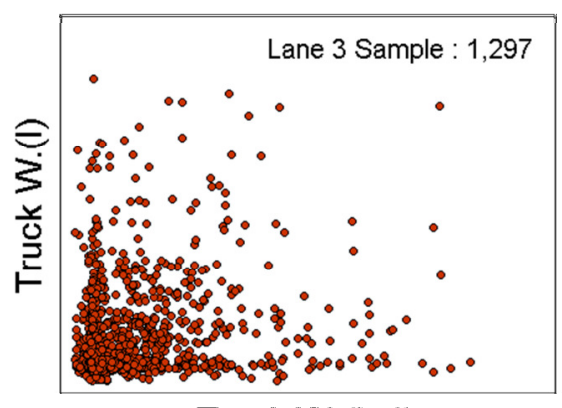

Truck $W,(1+1)$

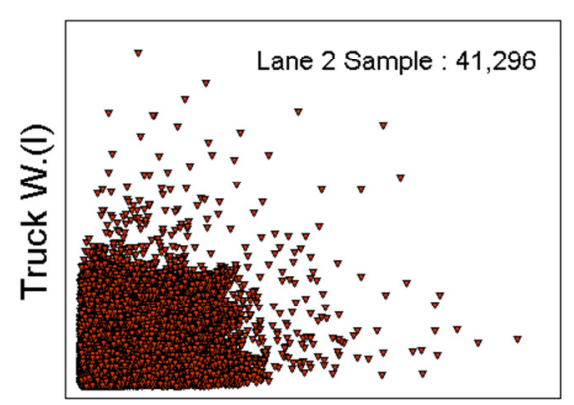

Truck W. $(1+1)$

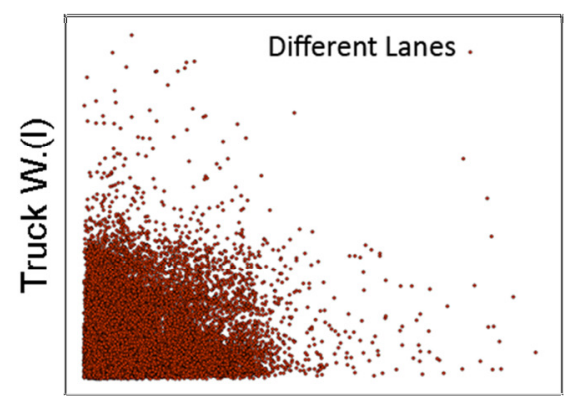

Truak W.(1+1)

Figure 1. Correlation of consecutive trucks in lane 1, lane 2, lane 3 and in different lanes 
As shown in Figure 1, WIM data collected from several sites in New York State show that there is no correlation between the weights of trucks close to each other in the same lane or in adjacent lanes. Hence, the probability density function of the effect of two trucks $\mathrm{f}_{\mathrm{s}}(\mathrm{S})$ can be calculated using a convolution equation presented as:

$$
f_{x s}\left(X_{s}\right)=\int_{-\infty}^{+\infty} f_{x 2}\left(X_{s}-x_{1}\right) f_{x 1}\left(x_{1}\right) d x_{1}
$$

where $f_{x s}(\ldots)$ is the probability distribution of the side-by-side effects, $f_{x 1}(\ldots)$ is the probability distribution of the effects of trucks in lane $1, \mathrm{f}_{\mathrm{x} 2}(\ldots)$ is the probability distribution of the effects of trucks in lane 2. The cumulative distributions $F_{s}(S)$ of the single lane loading event or that of the side-by-side event can be obtained by integrating $f_{x 1}(\ldots)$ and $f_{x s}(\ldots)$ so that $F_{s}(S)$ denotes the probability that the load effect, $s$, is less or equal to a value equal to $S$.

A bridge structure should be designed to withstand the maximum load effect expected over the service life of the bridge. For example, the AASHTO LRFD code specifies a design life of 75 years. In the case of the Eurocodes, the design life for bridges is 100 years. The LRFR bridge load rating from AASHTO also requires checking the capacity to resist the maximum load effects in a 5-yr rating period while bridges should be inspected every two years. It is simply impossible to get enough data to determine the maximum load effect expected over 75 or 100 years of loading. Even collecting sufficient data for a two-year inspection period would require several cycles of two-year data and one is never assured that data collected in the past will actually represent future load spectra. Therefore, some form of statistical projection should be performed with the collected WIM data. The proposed calculation procedure uses the cumulative 
distribution function for individual loading events and then applies a statistical projection to obtain the information required for a 1-year, 2-year, 75-year or 100-year service or design life.

To find the cumulative distribution for the maximum loading event in a period of time, $\mathrm{T}$, we have to start by estimating the number of loading events, $\mathrm{N}$, that may occur during this period. These events are designated as $S_{1}, S_{2} \ldots S_{N}$. The maximum of these $\mathrm{N}$ events, call it $\mathrm{S}_{\max , \mathrm{N}}$, is defined as:

$S_{\max , N}=\max \left(S_{1}, S_{2}, \ldots S_{N}\right)$

The cumulative probability distribution of $\mathrm{S}_{\max , \mathrm{N}}, \mathrm{F}_{\mathrm{s} \max \mathrm{N}}(\mathrm{S})$, gives the probability that $S_{\max , \mathrm{N}}$ is less or equal to a value $\mathrm{S}$. If $\mathrm{S}_{\max , \mathrm{N}}$ is less than $\mathrm{S}$, this implies that all the $\mathrm{S}_{\mathrm{i}}$ are less than S. Hence, assuming that the loading events are independent (this can be justified based on Figure 1) but drawn from the same probability distribution, the probability that $S_{\max , \mathrm{N}} \leq \mathrm{S}$ can be calculated from:

$$
F_{s_{\max }}(S)=\left[F_{s}(S)\right]^{N}
$$

The number of events $\mathrm{N}$ to be used in Eq. (4) can be easily obtained from the WIM data for either the single lane loading cases or multiple truck events. It is interesting to note that for simple span bridges, several analyses using Eq. (4) have shown that when the truck weight data include a large percentage of overloaded or permit trucks, the single truck event would govern the maximum loading of the bridge producing an $\mathrm{F}_{\mathrm{s} \text { max } \mathrm{N}}(\mathrm{S})$ curve to the right of that of the side-by-side case; whereas for sites where all heavy trucks are within or close to the legal limits, the side-by-side case governs (NCHRP 2011, Ghosn et al. 2013). 
The implementation of Eq. (4) is straight forward only if the cumulative distribution function $\mathrm{F}_{\mathrm{s}}(\mathrm{S})$ is well defined with high precision in the upper tail end for large values of S. However, in practice the use of Eq. (4) is not directly possible for large values of $\mathrm{N}$ when the upper range of $\mathrm{F}_{\mathrm{s}}(\mathrm{S})$ is not well defined and it is necessary to execute some form of statistical projection of the tail end of $F_{s}(S)$.

To address the problem, researchers have proposed different methods to extrapolate the results from the limited number of WIM observations that can be collected in the field. For example, O’Brien and his colleagues (Enright et al. 2010, Enright and O’Brien 2013) have resorted to curve fitting and extrapolating the basic truck gross and axle weight histograms as well as the probability distribution of the headways. They used the fitted models in a Monte Carlo simulation program running for millions of cycles to obtain a cumulative distribution $\mathrm{F}_{\mathrm{s}}(\mathrm{S})$ with a very long extrapolated tail that can be either used directly into Eq. (4) to find the probability distribution of the maximum load effect $\mathrm{F}_{\mathrm{S} \max \mathrm{N}}(\mathrm{S})$ or to find the load effect corresponding to a specified return period. Other researchers (Nowak 1999, Moses 2001, NCHRP 2011) have opted for less demanding extrapolation approaches that are significantly more efficient and easier to implement than the Monte Carlo simulations advocated by Enright et al. (2010). The alternative projection techniques are significantly more efficient and easier to implement but still yield similar results to those of the Monte Carlo simulations. Specifically, Ghosn and Sivakumar (Ghosn and Sivakumar 2010, NCHRP 2011) proposed a systematic step-by-step approach that is easy to implement in engineering practice on a routine basis. While the proposed method does not differ much from other methods such as that followed by Nowak, Ghosn and Sivakumar removed much of the subjective decision-making steps that other researchers have used so that the 
extrapolation can be executed following simple rules that have been demonstrated to work well with several data sets assembled from different WIM sites in the U.S. In this paper, the authors review the extrapolation rules proposed by Ghosn and Sivakumar and verify their applicability to two sets of WIM data. The first set was collected on one site in New York State and the other in Slovenia. A few variations on the approach are also proposed to further simplify the procedure. A parametric analysis is performed to investigate the sensitivity of the results to the quality and quantity of WIM data available for executing the extrapolation.

\section{Description of the model}

To illustrate the procedure, one year of WIM data representing 531,445 trucks was obtained for the North Bound direction of the I-81 Highway in upstate New York for analysis. Each truck was sent through the influence line for the moment at the mid-span of a $20 \mathrm{~m}$ bridge. The moments were then normalized as a function of the moment effect of the HL-93 load in the AASHTO Code and assembled into a histogram as shown in Figure 2 for both lanes of traffic (drive and passing lane). As shown in Figure 2, the probability distribution of the single loading event does not follow any known probability distribution type. However, the plot of the data for the drive lane on normal probability scale (Figure 3) shows that the upper 5\% of the data falls along a straight line with a regression coefficient $\mathrm{R}^{2}=0.997$. This means that the upper $5 \%$ matches that of a hypothetical normal distribution with a mean value $\mu_{\text {event }}=0.023$ and a standard deviation value $\sigma_{\text {event }}=0.33$. A similar result is obtained for the case of the passing lane. 

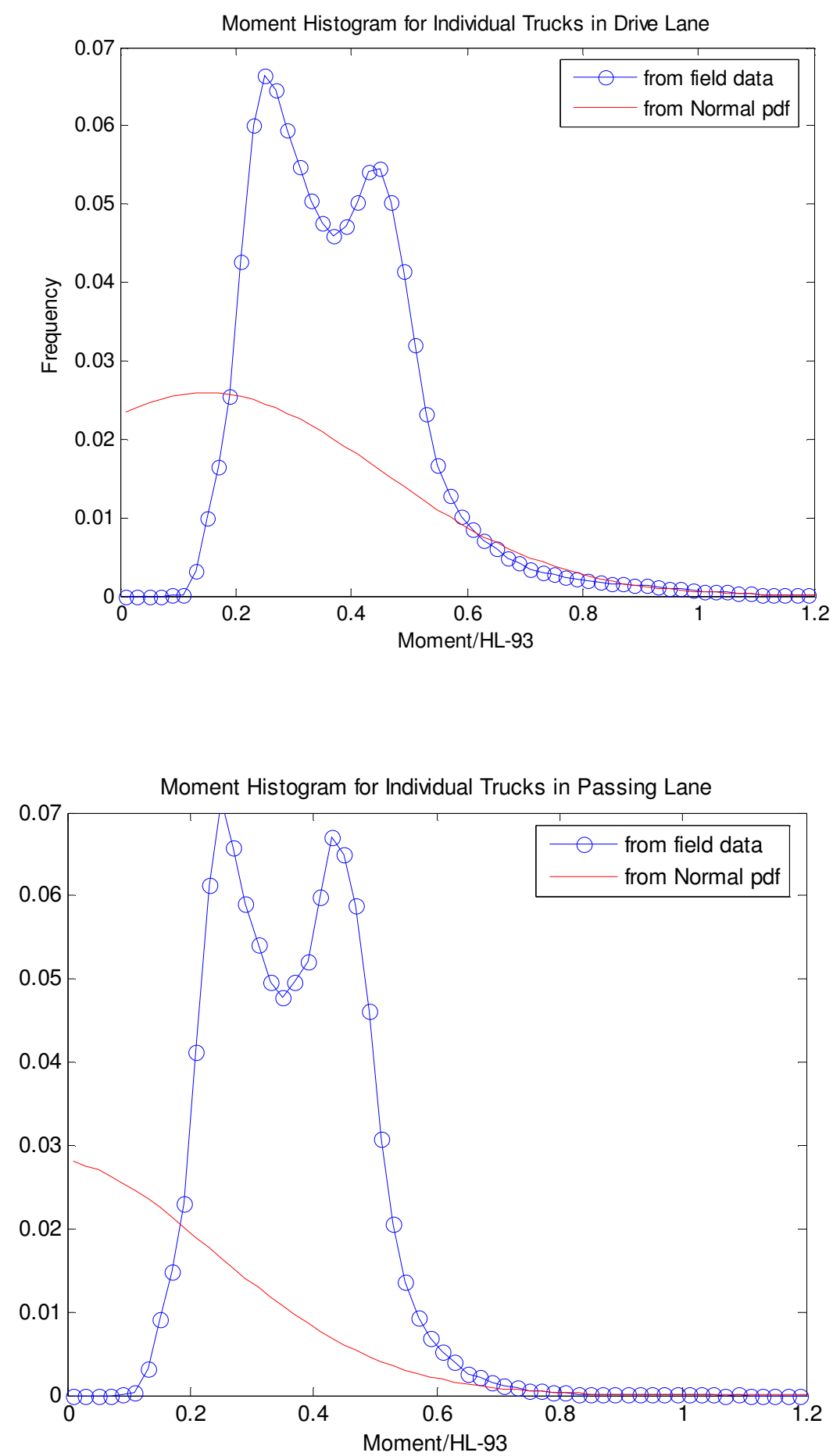

Figure 2. Normalized moment histogram for trucks in drive lane (up) and in passing lane (bottom) of I-81 NB. 


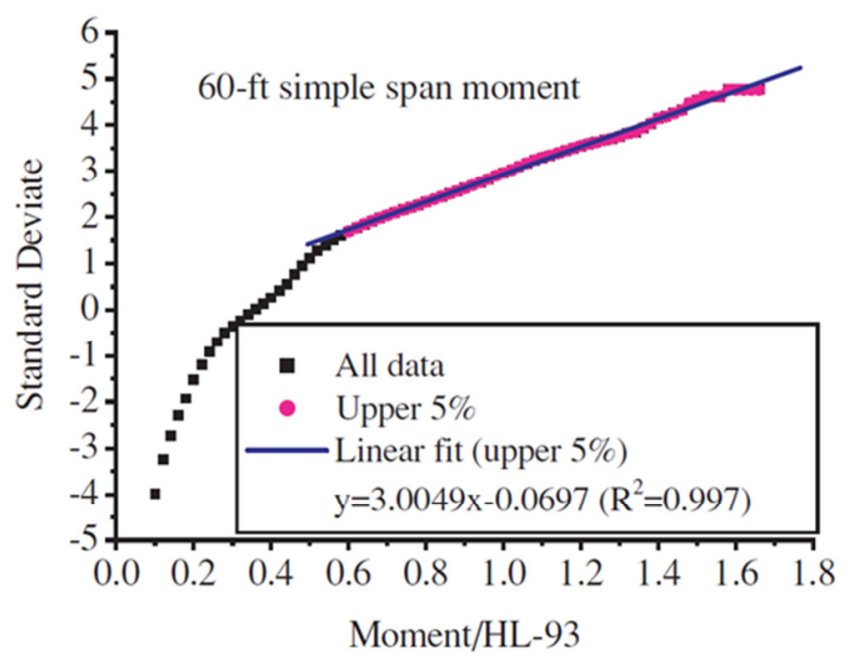

Figure 3. Normal probability plot of I-81 data (drive lane)

Similar observations regarding fitting the tail end on Normal probability plots are made when analyzing truck data from very different locations (NCHRP, 2011). The observations seem to be valid for data collected in the US as well as Europe as shown in Figure 4, that plots normalized moment effect on a 30-m simple span from WIM truck data recorded on a Slovenian highway (ARCHES D-08). In this case, the normal distribution fit was executed directly on the tail of the histogram by a least-square minimization error method as shown in figure 4.

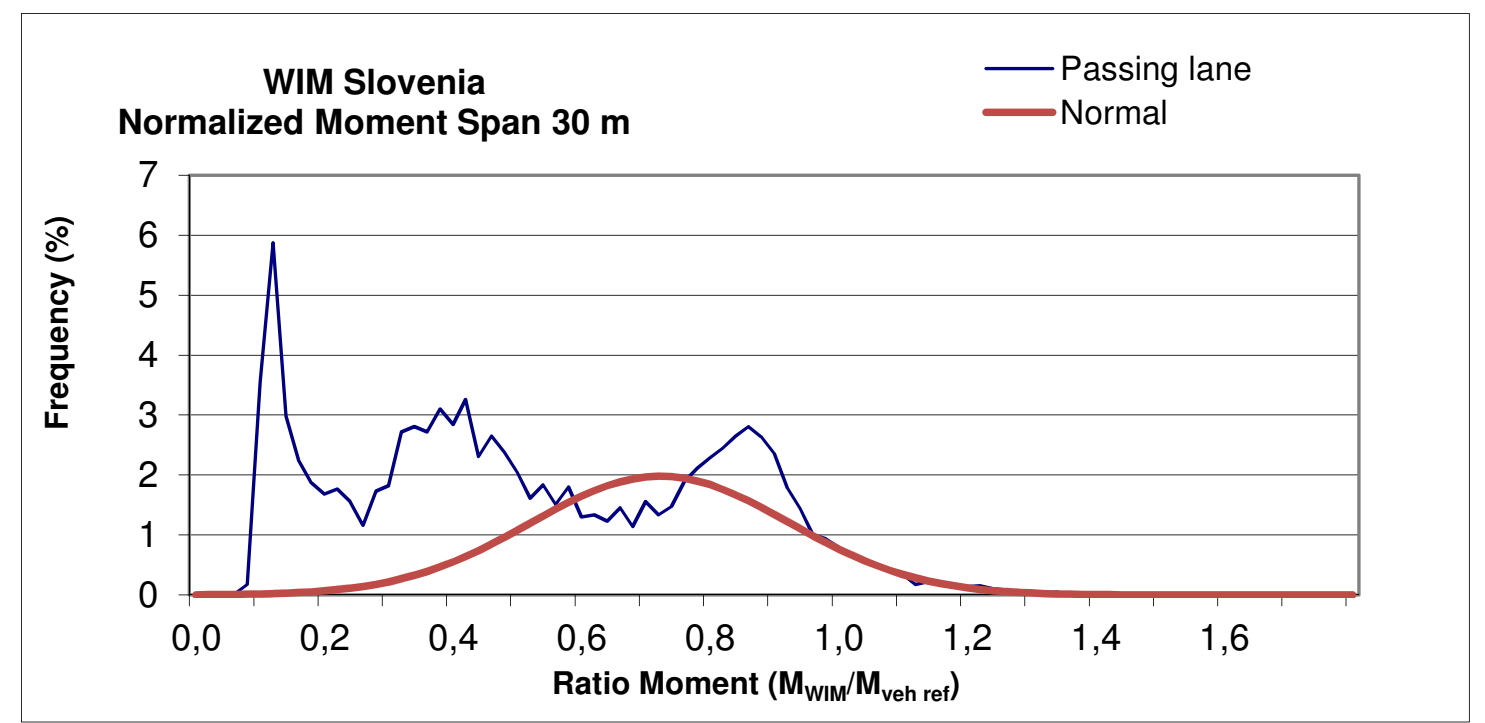




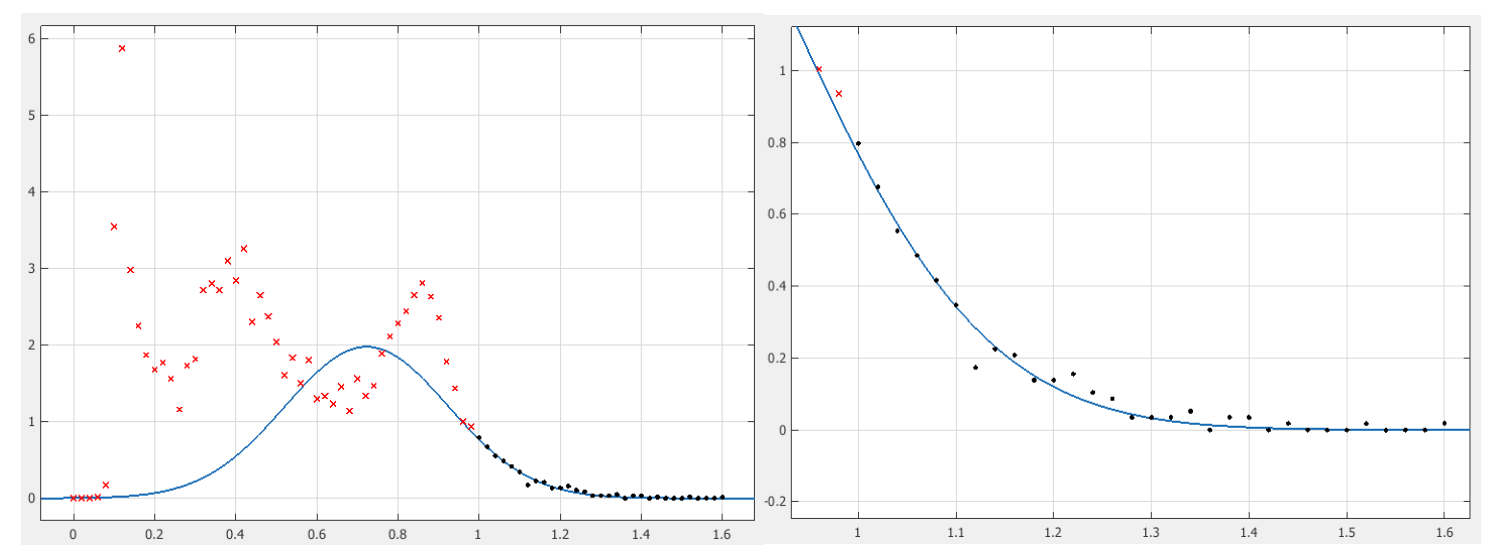

Figure 4. Normalized moment histogram for a $30 \mathrm{~m}$ span and a detail of regression fit at the upper tail with Normal distribution (Slovenian traffic, passing lane)

For high values of $N$, the application of Eq. (4) is controlled by the tail end of $F_{s}(S)$ near the upper $5 \%$ of the data. Since this region matches that of a normally distributed random variable, a closed form representation of the mean and standard deviation of $\mathrm{S}_{\max }$ can be directly obtained from the mean and standard deviation of a single event $\mu_{\text {event }}$ and $\sigma_{\text {event }}$. The projection is based on extreme value principles, which state that if the parent distribution of a variable, S, follows a normal probability function, the distribution of the maximum value $\mathrm{S}_{\max }$ approaches a Gumbel distribution as $\mathrm{N}$ increases with an inverse dispersion coefficient $\alpha_{N}$ given by (Ang \& Tang 2006):

$$
\alpha_{N}=\frac{\sqrt{2 \ln (N)}}{\sigma_{X}}
$$

and a most probable value given by:

$$
u_{N}=\mu_{X}+\sigma_{X}\left(\sqrt{2 \ln (N)}-\frac{\ln (\ln (N))+\ln (4 \pi)}{2 \sqrt{2 \ln (N)}}\right)
$$


This will lead to a mean of the maximum load effect:

$$
L_{\max }=\mu_{\max }=u_{N}+\frac{0.577216}{\alpha_{N}}
$$

and a standard deviation:

$$
\sigma_{\max }=\frac{\pi}{\sqrt{6} \alpha_{N}}
$$

\section{Projection approach}

While the statistical projection method used by Ghosn and Sivakumar (2010) is based on extreme value theory, other researchers (Nowak, 1999; Moses, 2001; Enright, et al., 2010) used the return period concept whereby the plotted cumulative distribution data is fitted through a curve that is extrapolated to obtain the probability of exceedance corresponding to the number of events in a given period, $\mathrm{T}_{\mathrm{r}}$. That is, if a 75 -yr period is selected for a bridge that is expected to be crossed by 2000 trucks/day, the value of the load corresponding to a probability of exceedance $F_{S}(S)=1 / N$ where $N=2000 \times 365 \times T_{r}$ is used to estimate the maximum load expected in a 75-yr service period.

Another approach consists of taking the maximum load observed within a basic unit of time, estimating the probability distribution of the maximum value and then applying Eq. (4) where $\mathrm{N}$ in this case is the ratio between the basic time unit and the service period. For example, Fu et al (2011) assembled a histogram of the maximum monthly load, fitted that histogram into a Gumbel probability distribution and raised the cumulative distribution of the Gumbel to a power $\mathrm{N}=12 \times 75$ to obtain the distribution of the maximum load in 75 years. As observed in NCHRP (2011), the maximum monthly fit approach will yield similar results as those of the model presented here assuming that 
the data is stationary and that the truck traffic pattern and truck weights are essentially similar throughout the year. However, by ignoring much of the data and concentrating only on the maximum observed over a relatively large time period, the approach may yield inaccurate results if for example, a one month period is exposed to a large number of high loads which will all be ignored except for a single one of these. Also, the maximum monthly fit approach will require very long periods of data collection in order to collect sufficient numbers of monthly maxima to obtain a good fit for the probability distribution function. In order to increase the data set one could resort to fitting the maxima from shorter periods such as the weekly maxima or daily maxima. However, in these cases, the goodness of the Gumbel fit distribution is reduced. In fact, the data analyzed as part of NCHRP 12-76 (NCHRP-2011) demonstrate that although the maximum load over an extended period of time may approach a Gumbel distribution, the same is not necessarily true for the maximum load observed over a one-week or one-month period. This has led some researchers to use generalized forms of the extreme value distribution fitted to the one-day maxima (O'Brien et al 2015). It should be noted however that fitting the maxima of short durations will emphasize the contributions of the lower end of the data set rather than those in the tail end which do contribute the most to the service life maxima. Using the wrong distribution has an important influence on the final result.

A set of analyses are performed to compare the results using different fitting approaches and study the effect of errors in the distribution type. Table 1 compares the results obtained in NCHRP 12-76 by Sivakumar et al. (NCHRP-2011) for the maximum projected normalized moment effect for the $20 \mathrm{~m}$ simple span bridge using: 1) a Normal distribution fit to the tail end of the WIM data, 2) a Gumbel distribution fit to the tail end of the maximum one-week load as extracted from the WIM data and 3) the projected normal 
distribution load for a return period corresponding to the service life, 4) a Gumbel

distribution fit to the tail end of the histogram and 5) a Lognormal distribution fit to the tail end of the load histogram. The following observations are made:

- The results of the normal fit, the weekly Gumbel fit and the normal return period give similar mean of maximum load value as the projection period increases.

- The use of the return period approach cannot provide the standard deviation of the maximum load value.

- The Gumbel fit to the weekly load requires the elimination of a large amount of the collected data and fitting only the tail end of the distribution of the maximum weekly load which reduces the confidence level in the projected mean value.

- Unless justified by a statistical evaluation of the data, using a lognormal or a Gumbel fit to the tail end would lead to large errors in the results.

Table 1. Effect of tail end model on mean and standard deviation of maximum load effect

\begin{tabular}{llllllllllllll}
\hline \multicolumn{1}{c}{ Drive lane loading } & \multicolumn{1}{c}{ Side-by-side loading } \\
\hline \multicolumn{1}{l}{ Projection period } & one week & two years & 75 years & one week & two years & 75 years \\
\hline & M. & S.D. & M. & S.D. & M. & S.D. & M. & S.D. & M. & S.D. & M. & S.D. \\
\hline $\begin{array}{l}\text { Normal fit to tail } \\
\text { end of WIM hist. }\end{array}$ & 1.36 & 0.091 & 1.67 & 0.074 & 1.87 & 0.066 & 1.21 & 0.171 & 1.75 & 0.122 & 2.08 & 0.104 \\
\hline $\begin{array}{l}\text { Return period } \\
\text { approach }\end{array}$ & 1.31 & N.A. & 1.63 & N.A. & 1.84 & N.A. & 1.12 & N.A. & 1.69 & N.A. & 2.03 & N.A. \\
\hline $\begin{array}{l}\text { Gumbel fit to max. } \\
\text { weekly load }\end{array}$ & 1.37 & 0.068 & 1.62 & 0.068 & 1.81 & 0.068 & 1.44 & 0.099 & 1.80 & 0.099 & 2.08 & 0.099 \\
\hline $\begin{array}{l}\text { Lognormal fit to tail } \\
\text { end of WIM hist. }\end{array}$ & 0.95 & 0.122 & 1.22 & 0.099 & 1.48 & 0.089 & 1.50 & 0.091 & 1.77 & 0.067 & 1.91 & 0.058 \\
\hline $\begin{array}{l}\text { Gumbel fit to tail } \\
\text { end of WIM hist. }\end{array}$ & 1.51 & 0.089 & 1.78 & 0.073 & 1.97 & 0.065 & 2.30 & 0.233 & 2.96 & 0.172 & 3.30 & 0.141 \\
\hline
\end{tabular}

$\mathrm{M}=$ mean. S.D.= standard deviation

The fit of the WIM histogram's tail into a normal distribution helps simplify the multipresence problem. For example, for side-by-side trucks in two-lane bridges, the convolution in Eq. 2, reduces to a normal distribution with a mean value equal to the 
sum of the mean of trucks' load effects in the drive lane to that of the trucks' in the passing lane. The standard deviation of the combined effect is the square root of the sum of the squares if the loads in the two lanes are independent.

As mentioned before, another issue is related to the technique used to obtain the statistics of the fitted tail end. For example, Sivakumar et al. (NCHRP 2011), following Nowak (1999) used a linear regression fit to the tail end of the cumulative distribution plotted on normal probability scale to obtain the statistics of the normal distribution function that matches the tail end of the actual histogram. Another approach would directly use the frequency histogram to obtain statistics of the Normal distribution.

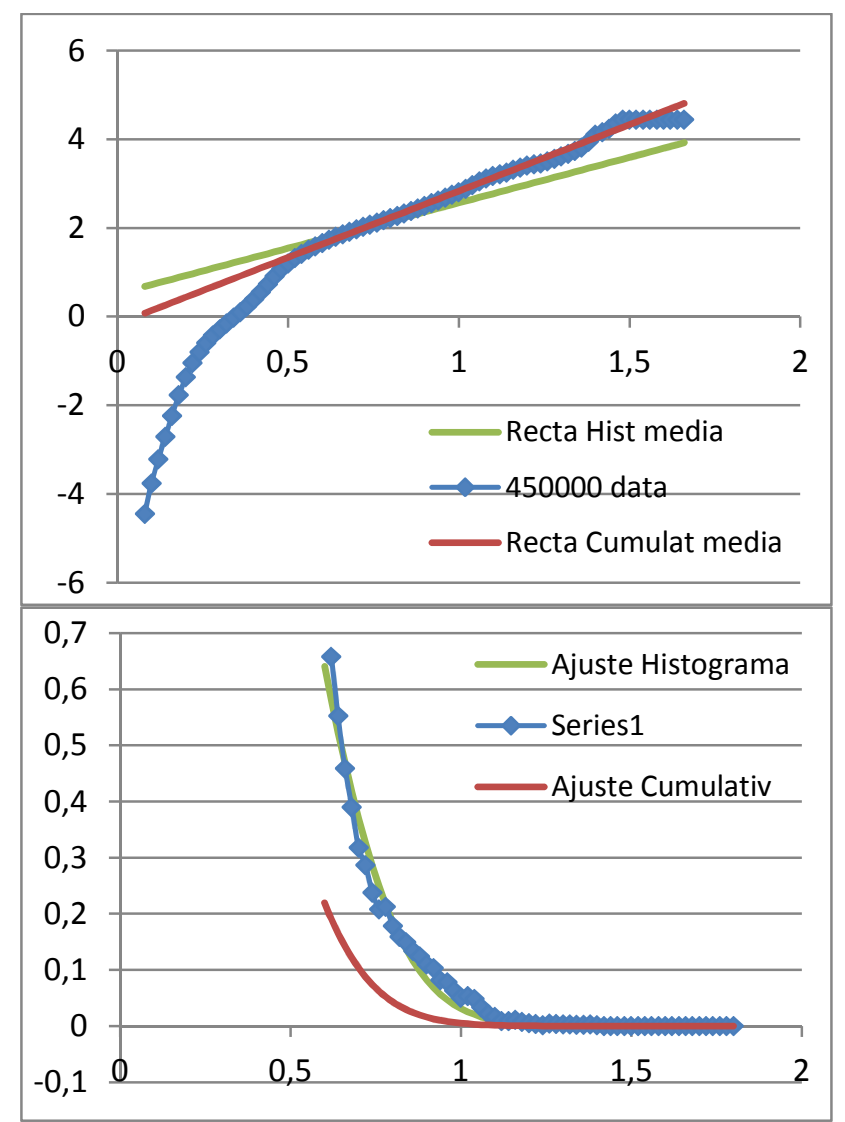

Figure 5. Comparison of fitting techniques: cumulative function or histogram. The best fit is different in both cases.

Experimentation with these two approaches have demonstrated that in certain cases, the two different fitting techniques may lead to seemingly different results as shown in 
Figure 5, that shows in red the goodness of the fit when it is executed on the cumulative distribution as compared to the goodness of the green fit when the statistics are extracted to match the tail end of the frequency histogram for the same data in blue plotted on a normal cumulative scale and on a frequency histogram. However, the effect of these errors on the projected maximum load are relatively small. For example, the mean and standard deviations of the normal distribution fitted to the tail end of the cumulative of the normalized moments of the $20 \mathrm{~m}$ bridge using a randomly selected 450,000 samples produce on the average $\mu_{\text {event }}=0.046$ and a standard deviation value $\sigma_{\text {event }}=0.29$ while the fit to the tail end of the frequency histogram would yield a mean $\mu_{\mathrm{event}}=0.25$ and a standard deviation value $\sigma_{\mathrm{event}}=0.27$. The projected maximum $75-\mathrm{yr}$ load in the first case would be $\mu_{\max }=1.81$ versus $\mu_{\max }=1.89$ in the second case. This demonstrates that errors in the mean value for one event are possible because this value happens to be close to zero but their effect on the projected service life maximum is within acceptable range of less than $5 \%$.

\section{Sensitivity analysis}

To verify the robustness of the proposed method for obtaining the maximum load effect, an analysis is carried out to check the sensitivity of the results to changes in the main parameters of the model.

\section{Effect of Tail-end of Truck Load Effect Histogram}

The analysis of the WIM data histogram used in this study shows that the tail end of the data in the drive lane matches the tail end of a Normal distribution with a mean $\mu_{\mathrm{x} 1}=0.1472$ and a standard deviation $\sigma_{\mathrm{x} 1}=0.3074$. Similarly, the tail end of the histogram for the passing lane shows that it matches that of a Normal distribution with 
mean $\mu_{\mathrm{x} 2}=-0.0417$ and a standard deviation $\sigma_{\mathrm{x} 2}=0.2797$. In this section, we study how a change in these parameters will affect the values of the expected maximum load effect, $\mathrm{L}_{\max }$, for the two-year and 75-year time periods. A simulation is executed to produce a histogram having a tail end that reflects the changes in these mean and standard deviation values. In a first step, the mean values of the Normal distributions of the drive lane and the passing lane are changed simultaneously by the same ratio while the standard deviations are kept at their original values. In the second step, the standard deviations of the drive lane and passing lanes are changed by the same ratio while the mean values are kept at their original values. The convolution approach with the Gumbel projection is performed and the results of $\mathrm{L}_{\max }$ are provided in Table 2. The third and fourth columns give the mean and standard deviations of $\mathrm{L}_{\max }$ for the two-year return period. The fourth and fifth columns give the mean and standard deviations of $\mathrm{L}_{\max }$ for the 75 -year return period. The results in Table 2 show that the mean value of $\mathrm{L}_{\max }$ is not significantly affected when the mean value of the Normal distribution is changed. Specifically, a change of $20 \%$ in the mean value of the equivalent normal distribution that matches the tail end of the load effect histogram leads to a change of less than $1.5 \%$ in the expected maximum load effect $\mathrm{L}_{\max }$. On the other hand, the table shows that $\mathrm{L}_{\max }$ is more sensitive to changes in the standard deviation of the equivalent Normal distribution. For example, when the standard deviation is changed by a factor of $10 \%$, the expected maximum load effect changes by as much as $7.6 \%$.

The analysis performed in this section was based on creating simulated data in the upper $5 \%$ of the truck load effect histogram. Because of the simulated data, the results for the base case when the mean is $1.0 \mu_{\mathrm{x}}$ and the standard deviation is $1.0 \sigma_{\mathrm{x}}$, are slightly different than those obtained from the original histogram. Also, the analysis assumes that the tail end matches that of a Normal distribution. 
Table 2. Sensitivity of expected maximum load effect $\mathrm{L}_{\max }$ to changes in statistical properties of histogram's tail end.

\begin{tabular}{|c|c|c|c|c|c|}
\hline & & $\begin{array}{l}\text { Mean of tail } \\
\left(\mu_{x}=\text { original }\right. \\
\text { mean })\end{array}$ & $\begin{array}{l}\text { Stand. Dev. } \\
\text { of tail } \\
\left(\sigma_{x}=\text { original }\right)\end{array}$ & $\begin{array}{l}\mathrm{L}_{\max } \text { for } \\
\text { 2-year max. }\end{array}$ & $\begin{array}{l}\mathrm{L}_{\max } \text { for } \\
75 \text {-year max }\end{array}$ \\
\hline \multirow{10}{*}{$\begin{array}{l}\text { Side-by-side } \\
\text { loading }\end{array}$} & \multirow{5}{*}{$\begin{array}{l}\text { Effect of } \\
\text { change in } \\
\mu_{\mathrm{x}}\end{array}$} & $0.80 \mu_{\mathrm{x}}$ & $1.00 \sigma_{\mathrm{x}}$ & 1.772 & 2.021 \\
\hline & & $0.90 \mu_{\mathrm{x}}$ & $1.00 \sigma_{\mathrm{x}}$ & 1.780 & 2.030 \\
\hline & & $1.00 \mu_{\mathrm{x}}$ & $1.00 \sigma_{\mathrm{x}}$ & 1.789 & 2.038 \\
\hline & & $1.10 \mu_{\mathrm{x}}$ & $1.00 \sigma_{\mathrm{x}}$ & 1.797 & 2.047 \\
\hline & & $1.20 \mu_{\mathrm{x}}$ & $1.00 \sigma_{\mathrm{x}}$ & 1.805 & 2.055 \\
\hline & \multirow{5}{*}{$\begin{array}{l}\text { Effect of } \\
\text { change in } \\
\sigma_{x}\end{array}$} & $1.00 \mu_{\mathrm{x}}$ & $0.90 \sigma_{\mathrm{x}}$ & 1.678 & 1.889 \\
\hline & & $1.00 \mu_{\mathrm{x}}$ & $0.95 \sigma_{\mathrm{x}}$ & 1.734 & 1.962 \\
\hline & & $1.00 \mu_{\mathrm{x}}$ & $1.00 \sigma_{\mathrm{x}}$ & 1.789 & 2.038 \\
\hline & & $1.00 \mu_{\mathrm{x}}$ & $1.05 \sigma_{\mathrm{x}}$ & 1.845 & 2.115 \\
\hline & & $1.00 \mu_{\mathrm{x}}$ & $1.10 \sigma_{\mathrm{x}}$ & 1.902 & 2.193 \\
\hline \multirow{10}{*}{$\begin{array}{l}\text { Drive lane } \\
\text { loading }\end{array}$} & \multirow{5}{*}{$\begin{array}{l}\text { Effect of } \\
\text { change in } \\
\mu_{x}\end{array}$} & $0.80 \mu_{\mathrm{x}}$ & $1.00 \sigma_{\mathrm{x}}$ & 1.570 & 1.759 \\
\hline & & $0.90 \mu_{\mathrm{x}}$ & $1.00 \sigma_{\mathrm{x}}$ & 1.582 & 1.771 \\
\hline & & $1.00 \mu_{\mathrm{x}}$ & $1.00 \sigma_{\mathrm{x}}$ & 1.593 & 1.784 \\
\hline & & $1.10 \mu_{\mathrm{x}}$ & $1.00 \sigma_{\mathrm{x}}$ & 1.604 & 1.796 \\
\hline & & $1.20 \mu_{\mathrm{x}}$ & $1.00 \sigma_{\mathrm{x}}$ & 1.616 & 1.809 \\
\hline & \multirow{5}{*}{$\begin{array}{l}\text { Effect of } \\
\text { change in } \\
\sigma_{x}\end{array}$} & $1.00 \mu_{\mathrm{x}}$ & $0.90 \sigma_{x}$ & 1.482 & 1.652 \\
\hline & & $1.00 \mu_{\mathrm{x}}$ & $0.95 \sigma_{\mathrm{x}}$ & 1.539 & 1.719 \\
\hline & & $1.00 \mu_{\mathrm{x}}$ & $1.00 \sigma_{\mathrm{x}}$ & 1.593 & 1.784 \\
\hline & & $1.00 \mu_{\mathrm{x}}$ & $1.05 \sigma_{\mathrm{x}}$ & 1.644 & 1.844 \\
\hline & & $1.00 \mu_{\mathrm{x}}$ & $1.10 \sigma_{\mathrm{x}}$ & 1.692 & 1.901 \\
\hline
\end{tabular}

\section{Effect of shorter term data}

Sivakumar et al. (NCHRP 2011) recommend that at least one year of WIM data be collected for use in projecting the maximum load effect for the purpose of evaluating the safety of bridges. This recommendation is made in order to ensure that sufficient numbers of samples are available to give an accurate representation of the tail end of the histogram and also to account for any seasonal changes in the truck traffic pattern and gross weights. 
Table 3. Effect of reduced data on tail end representation and maximum load (fit to the histogram)

\begin{tabular}{llllllllll}
\hline $\begin{array}{l}\text { WIM } \\
\text { data } \\
\text { samples }\end{array}$ & $\begin{array}{l}\text { Approx. } \\
\text { monitoring } \\
\text { period }\end{array}$ & $\begin{array}{l}\text { Mean } \\
\mu_{\text {event }} \\
\text { min. }\end{array}$ & $\begin{array}{l}\text { Mean } \\
\mu_{\text {event }} \\
\text { average }\end{array}$ & $\begin{array}{l}\text { St. dev } \\
\sigma_{\text {event }} \\
\text { min. }\end{array}$ & $\begin{array}{l}\text { St.dev } \\
\sigma_{\text {event }} \\
\text { average }\end{array}$ & $\begin{array}{l}\text { Mean } \\
\mu_{\max } \\
\text { min. }\end{array}$ & $\begin{array}{l}\text { Mean } \\
\mu_{\max } \\
\text { average }\end{array}$ & $\begin{array}{l}\text { St. dev } \\
\sigma_{\max } \\
\text { min. }\end{array}$ & $\begin{array}{l}\text { St. dev } \\
\sigma_{\max } \\
\text { average }\end{array}$ \\
\hline 531,445 & 12 months & -- & 0.2412 & -- & 0.27 & -- & 1.8712 & -- & 0.058 \\
450,000 & 10 months & 0.237500 & 0.24583 & 0.267400 & 0.272115 & 1.865516 & 1.8886 & 0.0597490 & 0.058455 \\
360,000 & 8 months & 0.238300 & 0.24583 & 0.265200 & 0.271860 & 1.855234 & 1.8871 & 0.0595122 & 0.058396 \\
270,000 & 6 months & 0.238500 & 0.24826 & 0.261600 & 0.270370 & 1.838601 & 1.8805 & 0.0598130 & 0.058073 \\
180,000 & 4 months & 0.235400 & 0.24785 & 0.259000 & 0.272515 & 1.826404 & 1.8930 & 0.0606294 & 0.058509 \\
90,000 & 2 months & 0.234400 & 0.24817 & 0.259300 & 0.269860 & 1.829415 & 1.8773 & 0.0601353 & 0.057941 \\
45,000 & 1 month & 0.210900 & 0.25045 & 0.242900 & 0.269740 & 1.746707 & 1.8789 & 0.0652916 & 0.057816 \\
21,000 & 2 weeks & 0.166700 & 0.24139 & 0.243700 & 0.275505 & 1.750837 & 1.9046 & 0.0704693 & 0.058920 \\
\hline
\end{tabular}

Table 4. Effect of reduced data on tail end representation and maximum load (fit to the cumulative)

\begin{tabular}{llllllllll}
\hline $\begin{array}{l}\text { WIM } \\
\text { data } \\
\text { samples }\end{array}$ & $\begin{array}{l}\text { Approx. } \\
\text { monitoring } \\
\text { period }\end{array}$ & $\begin{array}{l}\text { Mean } \\
\mu_{\text {event }} \\
\text { min. }\end{array}$ & $\begin{array}{l}\text { Mean } \\
\mu_{\text {event }} \\
\text { average }\end{array}$ & $\begin{array}{l}\text { St. dev } \\
\sigma_{\text {event }} \\
\text { min. }\end{array}$ & $\begin{array}{l}\text { St. dev } \\
\sigma_{\text {event }} \\
\text { average }\end{array}$ & $\begin{array}{l}\text { Mean } \\
\mu_{\max } \\
\text { min. }\end{array}$ & $\begin{array}{l}\text { Mean } \\
\mu_{\max } \\
\text { average }\end{array}$ & $\begin{array}{l}\text { St. dev } \\
\sigma_{\max } \\
\text { min. }\end{array}$ & $\begin{array}{l}\text { St. dev } \\
\text { average }\end{array}$ \\
\hline 531,445 & 12 months & -- & 0.0548 & -- & 0.2867 & -- & 1785 & -- & 0.08249 \\
450,000 & 10 months & -0.05447 & 0.046348 & 0.247783 & 0.291350 & 1.577757 & 1.8053 & 0.08197107 & 0.061750 \\
360,000 & 8 months & 0.017614 & 0.054057 & 0.183361 & 0.286113 & 1.281238 & 1.7813 & 0.07148727 & 0.060354 \\
270,000 & 6 months & 0.006473 & 0.041892 & 0.256334 & 0.300540 & 1.622054 & 1.8563 & 0.07540447 & 0.064600 \\
180,000 & 4 months & 0.001705 & 0.031759 & 0.230690 & 0.310294 & 1.417799 & 1.9050 & 0.07619192 & 0.065878 \\
90,000 & 2 months & 0.004071 & 0.050494 & 0.164885 & 0.294006 & 1.184273 & 1.8254 & 0.07588406 & 0.061330 \\
45,000 & 1 month & 0.011264 & 0.037795 & 0.211249 & 0.307120 & 1.378060 & 1.8919 & 0.7550530 & 0.064649 \\
21,000 & 2 weeks & 0.007574 & 0.051117 & 0.217588 & 0.305055 & 1.415754 & 1.8928 & 0.07648175 & 0.064489 \\
\hline
\end{tabular}

When evaluating the safety of existing bridges, it is often not possible to assemble an entire year's data. This is because very few bridges are fitted with permanent WIM systems that can provide long term data when needed. Instead, it is most common to use portable WIM systems that can be only deployed for short periods of time. To study the effect of shorter term data, a simulation is performed to study the effect of the reduction in the numbers of samples. This is executed by taking a random number of $\mathrm{N}$ samples from the WIM data for various values of $\mathrm{N}$ representing the equivalent of $10,8,6,4,2$ and 1 months and two weeks of data. The results of the smaller sample size on the mean and standard deviation of the hypothetical normal distribution representing the tail end of the single event and the projected mean and standard deviation of the maximum load 
effect are provided in Tables 3 and 4 . Of course, the analysis presented assumes that the bridge loading process is stationary where the parent distribution does not change with time neither in the short nor in the long terms. It is also understood that because of the random nature of the problem, different simulations with the same number of samples may produce different results. Therefore, Tables 3 and 4 include the minimum as well as the average from 20 Monte Carlo runs for each sampling period. The minimum value is provided to give an approximation to the maximum error that could be obtained if a single set of data is used as compared to the average from 20 simulations.

Although the results in Tables 3 and 4 show large variations between the minimum values and the average values, no decipherable trend is observed in the average 75-year maximum obtained from 20 simulations, when the sampling period is changed. This indicates that what is important is to ensure that the sampling period should be targeted to catch representative data in the tail end of histogram rather than on the quantity of data. Of course taking data over the longest possible sampling period would minimize the chances of missing the heaviest trucks. Based on this observation, it is recommended that the deployment of WIM systems be carefully planned with input from traffic engineers to collect data over the longest period of time possible and ensure that the data collection coincides with periods of high truck traffic volumes and when truck with heavy cargo are in operation.

\section{Effect of inaccuracy in WIM data}

Another potential source of errors in the projected maximum load is the lack of accuracy of the WIM system used to collect the truck data. Any truck measurement system has inherent inaccuracies. Although a properly calibrated system will on the average produce accurate axle spacing and axle weights, some random errors are normally observed around the exact value for the best calibrated systems. Calibrated 
WIM systems have been found to produce errors with standard deviations ranging from around $+/-5 \%$ up to $+/-15 \%$ of the gross vehicle weights. For the purposes of this study, we will assume that a similar range of errors is obtained on the load effect. A sensitivity analysis is then performed to observe the effect of random errors on the projected maximum load. The results for the projected maximum load effect assuming a 12 month monitoring period are compared to the maximum load obtained from a 10-month and two-week monitoring period in Table 5. In this case also the values in Table 5 are obtained based on 20 Monte Carlo runs to account for the random nature of the data sampling process. Table 5 shows how the results are more sensitive to measurement errors when the normal fit is executed based on the tail end of the histogram while the projection of the maximum load effect obtained by fitting the cumulative probability plot on normal scale is less sensitive. Reducing the monitoring period from 10 months to 2 weeks does not significantly affect the results or amplify the effect of the errors.

Table 5. Effect of WIM measurement errors

\begin{tabular}{|c|c|c|c|c|c|}
\hline \multicolumn{6}{|c|}{ Histogram } \\
\hline $\begin{array}{l}\text { Stand } \\
\text { dev } \\
\text { of } \\
\text { error }\end{array}$ & $\begin{array}{l}\text { Monitoring } \\
\text { period }\end{array}$ & $\begin{array}{l}\text { Mean } \\
\mu_{\text {event }}\end{array}$ & $\begin{array}{l}\text { Stand } \\
\text { dev } \\
\sigma_{\text {event }}\end{array}$ & $\begin{array}{l}\text { Mean } \\
\mu_{\max }\end{array}$ & $\begin{array}{l}\text { Stand } \\
\text { dev } \\
\sigma_{\max }\end{array}$ \\
\hline $0 \%$ & 12 months & 0.2412 & 0.27 & 1.8712 & 0.058 \\
\hline $0 \%$ & 10 months & 0.2458 & 0.2721 & 1.8886 & 0.0586 \\
\hline $5 \%$ & 10 months & 0.2856 & 0.2429 & 1.7518 & 0.0521 \\
\hline $15 \%$ & 10 months & 0.3535 & 0.2043 & 1.5869 & 0.0439 \\
\hline $0 \%$ & 2 weeks & 0.2414 & 0.2755 & 1.9046 & 0.0589 \\
\hline $5 \%$ & 2 weeks & 0.2830 & 0.2446 & 1.7597 & 0.0524 \\
\hline $15 \%$ & 2 weeks & 0.3566 & 0.2010 & 1.5700 & 0.0431 \\
\hline \multicolumn{6}{|c|}{ Cumulative } \\
\hline $\begin{array}{l}\text { Stand } \\
\text { dev } \\
\text { of } \\
\text { error }\end{array}$ & $\begin{array}{l}\text { Monitoring } \\
\text { period }\end{array}$ & $\begin{array}{l}\text { Mean } \\
\mu_{\text {event }}\end{array}$ & $\begin{array}{l}\text { Stand } \\
\text { dev } \\
\sigma_{\text {event }}\end{array}$ & $\begin{array}{l}\text { Mean } \\
\mu_{\max }\end{array}$ & $\begin{array}{l}\text { Stand } \\
\text { dev } \\
\sigma_{\max }\end{array}$ \\
\hline $0 \%$ & 12 months & 0.0548 & 0.2867 & 1.785 & 0.0825 \\
\hline $0 \%$ & 10 months & 0.0463 & 0.2914 & 1.8053 & 0.0618 \\
\hline $5 \%$ & 10 months & 0.0064 & 0.3601 & 2.1672 & 0.0772 \\
\hline $15 \%$ & 10 months & 0.1214 & 0.3187 & 2.0452 & 0.0680 \\
\hline
\end{tabular}




\begin{tabular}{llllll}
$0 \%$ & 2 weeks & 0.0511 & 0.3051 & 1.8928 & 0.0645 \\
$5 \%$ & 2 weeks & 0.0016 & 0.3557 & 2.1492 & 0.0759 \\
$15 \%$ & 2 weeks & 0.1135 & 0.3197 & 2.0435 & 0.0666 \\
\hline
\end{tabular}

\section{Effect of Truck Traffic Intensity}

The number of loading events expected within a return period has been defined as $\mathrm{N}$ in Equation 4. Although this is an important parameter, previous studies have demonstrated that the final results asymptotically approach an upper limit as the number of events $\mathrm{N}$ increases. This would be especially true when the service life period exceeds 50 years as required for estimating the maximum load effects when designing new bridges. The object of this paragraph is to study how the number of loading events affects the results. The analysis performed in this section assumes that the number of loading events per day is changed from the 2000 events obtained from the WIM data while keeping the percentage of the trucks that are side-by-side, $\mathrm{P}_{\mathrm{sxs}}$, constant at $0.95 \%$ as obtained from I-81 NB WIM data. Similarly, the raw WIM load effect histograms for the trucks in the drive lane and those in the passing lane are kept the same. The range of values used for the number of loading events is varied from 500/day to 6000/day as shown in Tables 6 and 7 for the 75-year and 2-year projections.

The results of Tables 6 and 7 show that a decrease of the number of events by a factor of 4 (from 2000 to 500) leads to a reduction in the expected maximum 75-year load effect for the loading in the drive lane by $-6.59 \%$ while increasing the number of events by a factor of 3 (from 2000 to 6000) leads to an increase in the expected maximum load effect by $+3.26 \%$.

This demonstrates that even large errors in the determination of the number of loading events and in the estimation of the ADTT would produce only marginal errors in the estimated maximum load effect. This is due to the asymptotic nature of the problem 
whereby the results of equation 4 would converge as the number of events increases. It is noted that the results provided in Tables 6 and 7 assume that the percentage of events that are due to side-by-side trucks remains constant. The analysis of WIM data has shown that the percentage of side-by-side cases changes as the ADTT of the site changes. For instance, figure 5 shows a strong correlation between multi-presence and ADTT for the New York traffic data (NCHRP 2011).

1-81 NB, Multiple-Presence vs ADTT

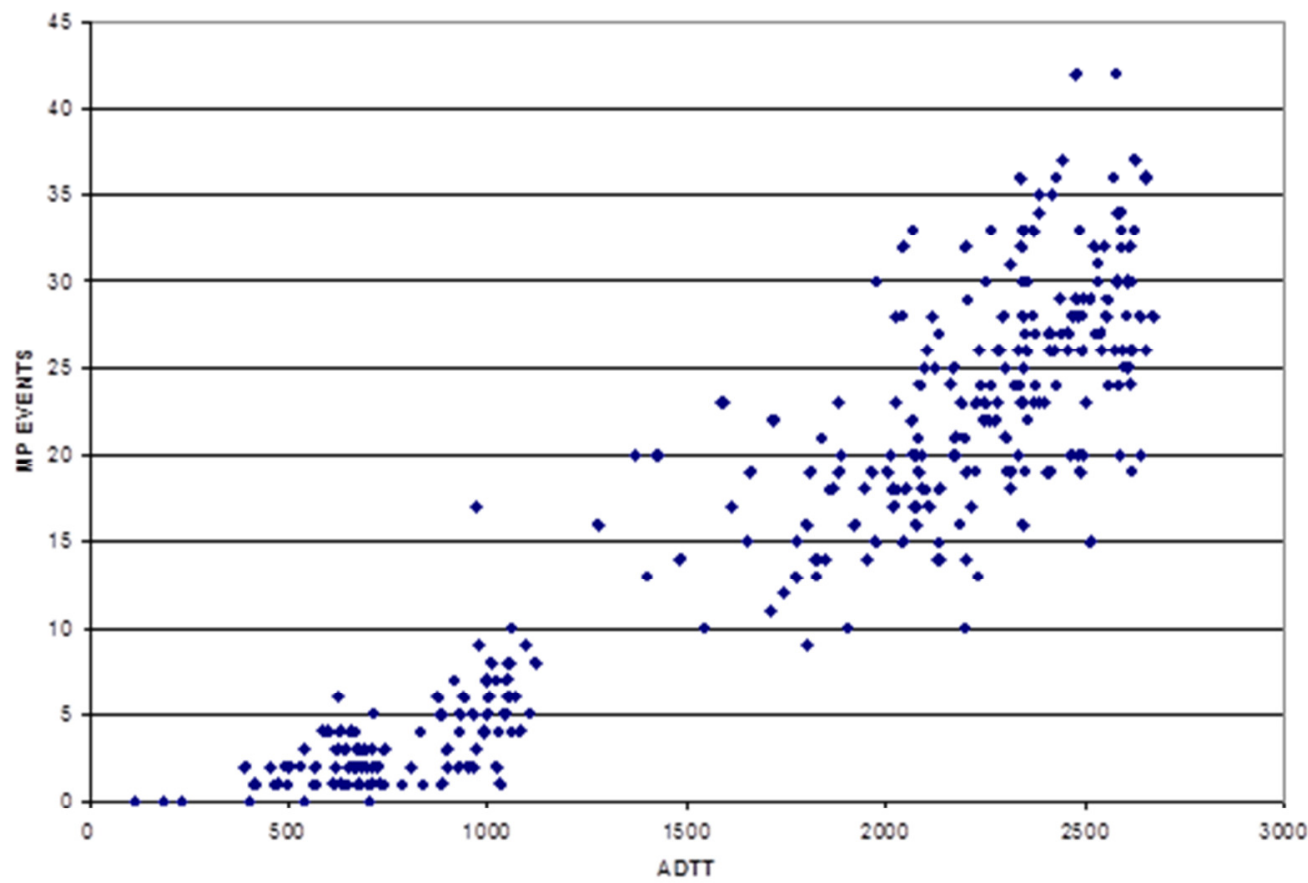

Figure 5. Side-by-side events vs. ADTT. I-81 NB New York

Table 6. Summary of results from I-81 NB site for different ADTT: 75-year period

\begin{tabular}{|c|c|c|c|}
\hline & & & $\begin{array}{l}\text { simplified } \\
\text { Gumbel }\end{array}$ \\
\hline \multirow[b]{7}{*}{ One lane } & \multirow{6}{*}{$\begin{array}{l}\text { Mean } \\
75 \text {-years }\end{array}$} & $\mathrm{N}=500 /$ day & 1.794 \\
\hline & & $\mathrm{N}=1000 /$ day & 1.832 \\
\hline & & $\mathrm{N}=2000 /$ day & 1.870 \\
\hline & & $\mathrm{N}=3000 /$ day & 1.891 \\
\hline & & $\mathrm{N}=4000 /$ day & 1.907 \\
\hline & & $\mathrm{N}=6000 /$ day & 1.928 \\
\hline & & $\mathrm{N}=500 /$ day & 0.069 \\
\hline
\end{tabular}




\begin{tabular}{|c|c|c|c|}
\hline \multirow[t]{5}{*}{ loading } & \multirow{5}{*}{$\begin{array}{l}\text { Standard } \\
\text { deviation } \\
75 \text {-years }\end{array}$} & $\mathrm{N}=1000 /$ day & 0.068 \\
\hline & & $\mathrm{N}=2000 /$ day & 0.066 \\
\hline & & $\mathrm{N}=3000 /$ day & 0.066 \\
\hline & & $\mathrm{N}=4000 /$ day & 0.065 \\
\hline & & $\mathrm{N}=6000 /$ day & 0.064 \\
\hline \multirow{12}{*}{$\begin{array}{l}\text { Side-by- } \\
\text { side } \\
\text { loading }\end{array}$} & \multirow{6}{*}{$\begin{array}{l}\text { Mean } \\
75 \text {-years }\end{array}$} & $\mathrm{N}=500 /$ day & 1.963 \\
\hline & & $\mathrm{N}=1000 /$ day & 2.024 \\
\hline & & $\mathrm{N}=2000 /$ day & 2.083 \\
\hline & & $\mathrm{N}=3000 /$ day & 2.117 \\
\hline & & $\mathrm{N}=4000 /$ day & 2.141 \\
\hline & & $\mathrm{N}=6000 /$ day & 2.174 \\
\hline & \multirow{6}{*}{$\begin{array}{l}\text { Standard } \\
\text { deviation } \\
75 \text {-years }\end{array}$} & $\mathrm{N}=500 /$ day & 0.110 \\
\hline & & $\mathrm{N}=1000 /$ day & 0.107 \\
\hline & & $\mathrm{N}=2000 /$ day & 0.104 \\
\hline & & $\mathrm{N}=3000 /$ day & 0.102 \\
\hline & & $\mathrm{N}=4000 /$ day & 0.101 \\
\hline & & $\mathrm{N}=6000 /$ day & 0.100 \\
\hline
\end{tabular}

Table 7. Summary of results from I-81 NB site for different ADTT: 2-year period

\begin{tabular}{|c|c|c|c|}
\hline & & & $\begin{array}{l}\text { Simplified } \\
\text { Gumbel }\end{array}$ \\
\hline \multirow{12}{*}{$\begin{array}{l}\text { One lane } \\
\text { loading }\end{array}$} & \multirow{6}{*}{$\begin{array}{l}\text { Mean } \\
\text { 2-years }\end{array}$} & $\mathrm{N}=500 /$ day & 1.579 \\
\hline & & $\mathrm{N}=1000 /$ day & 1.623 \\
\hline & & $\mathrm{N}=2000 /$ day & 1.665 \\
\hline & & $\mathrm{N}=3000 /$ day & 1.689 \\
\hline & & $\mathrm{N}=4000 /$ day & 1.706 \\
\hline & & $\mathrm{N}=6000 /$ day & 1.730 \\
\hline & \multirow{6}{*}{$\begin{array}{l}\text { Standard } \\
\text { deviation } \\
\text { 2-years }\end{array}$} & $\mathrm{N}=500 /$ day & 0.078 \\
\hline & & $\mathrm{N}=1000 /$ day & 0.076 \\
\hline & & $\mathrm{N}=2000 /$ day & 0.074 \\
\hline & & $\mathrm{N}=3000 /$ day & 0.073 \\
\hline & & $\mathrm{N}=4000 /$ day & 0.073 \\
\hline & & $\mathrm{N}=6000 /$ day & 0.072 \\
\hline \multirow{12}{*}{$\begin{array}{l}\text { Side-by- } \\
\text { side } \\
\text { loading }\end{array}$} & \multirow{6}{*}{$\begin{array}{l}\text { Mean } \\
\text { 2-years }\end{array}$} & $\mathrm{N}=500 /$ day & 1.609 \\
\hline & & $\mathrm{N}=1000 /$ day & 1.683 \\
\hline & & $\mathrm{N}=2000 /$ day & 1.753 \\
\hline & & $\mathrm{N}=3000 /$ day & 1.793 \\
\hline & & $\mathrm{N}=4000 /$ day & 1.820 \\
\hline & & $\mathrm{N}=6000 /$ day & 1.859 \\
\hline & \multirow{6}{*}{$\begin{array}{l}\text { Standard } \\
\text { deviation } \\
\text { 2-years }\end{array}$} & $\mathrm{N}=500 /$ day & 0.132 \\
\hline & & $\mathrm{N}=1000 /$ day & 0.127 \\
\hline & & $\mathrm{N}=2000 /$ day & 0.122 \\
\hline & & $\mathrm{N}=3000 /$ day & 0.120 \\
\hline & & $\mathrm{N}=4000 /$ day & 0.118 \\
\hline & & $\mathrm{N}=6000 /$ day & 0.116 \\
\hline
\end{tabular}




\section{Effect of Passing Rates}

A study of truck multiple-presence at 25 sites across New Jersey over a period of 11 years has also provided valuable data on the relationship between truck volume and truck multiple presence (Gindy and Nassif 2006). Obtaining reliable multiple-presence statistics requires large quantities of continuous WIM data with refined time stamps, which may not be available at every site. For this reason, it is important to study the effect of changes in the number of side-by-side events on the results of the maximum load effects. The effect of passing rates as expressed in terms of the percent of side-byside cases, $\mathrm{P}_{\mathrm{sxs}}$, on the values of the expected maximum load effects, $\mathrm{L}_{\max }$, is similar to the effect of changes in the number of events or ADTT in the sense that this will only affect the number of load repetitions $\mathrm{N}$ of equation 4 for the case of side-by-side trucks. For example, if the number of events per day is kept at 2000 and assuming that $6 \%$ of these events (instead of the actually measured by WIM and previously used $0.95 \%$ ) are side-by-side, then the total number of side-by-side cases in one day becomes 120 instead of the original 19. If the number of single truck events in the drive and passing lanes remain proportional to the original distribution, then one could expect that $84.04 \%$ of the events will be single trucks in the drive lane and $9.96 \%$ will be single trucks in the passing lane. Thus, the number of side-by-side events becomes 120 and the number of daily events in the drive lane $1800(2000 \times 84.04 \%+120)$. Notice how the 1800 number of events in the drive lane remains very close to the original 1790 obtained when $0.95 \%$ of the events are side-by-side. This indicates that the projection of the maximum load effect for the single lane cases will not be significantly affected by a change in the percentage of side-by-side trucks and that only the side-by-side cases will be affected. Even so, the changes in the maximum load effect, $\mathrm{L}_{\max }$, will be relatively small due to the asymptotic nature of the problem. This fact is illustrated in Table 8 
which shows how little change is observed in the expected 75-year and 2-year maximum load effects with the percentage of side-by-side cases for different ADTT. For example, a change in the percentage of side-by-side events from $0.5 \%$ to $6 \%$ or by a factor of $12(1200 \%)$ for a site with ADTT=2000 results in a change in the expected load effect, $\mathrm{L}_{\max }$, for the 2-year return period of only $11 \%$. Similar changes are observed for all the ADTT cases considered. These results indicate that even if the WIM data may contain large errors in the side-by-side count, the relative effect of these errors on the final results will not be significant.

Table 8. Effect of changes in side-by-side percentage on expected maximum load effect side-by-side cases only.

\begin{tabular}{|l|l|l|l|}
\hline ADTT & $\begin{array}{l}\text { Side-by-side } \\
\text { percentage } \mathrm{P}_{\text {sxs }}\end{array}$ & $\begin{array}{l}\text { Mean 2-year } \\
\text { maximum load } \\
\text { effect }\end{array}$ & $\begin{array}{l}\text { Mean 75-year } \\
\text { maximum load } \\
\text { effect }\end{array}$ \\
\hline \multirow{5}{*}{2000} & $0.5 \%$ & 1.749 & 2.029 \\
\cline { 2 - 4 } & $1 \%$ & 1.802 & 2.082 \\
\cline { 2 - 4 } & $2 \%$ & 1.856 & 2.136 \\
\cline { 2 - 4 } & $4 \%$ & 1.909 & 2.189 \\
\cline { 2 - 4 } & $6 \%$ & 1.941 & 2.220 \\
\hline \multirow{5}{*}{4000} & $0.5 \%$ & 1.802 & 2.082 \\
\cline { 2 - 4 } & $1 \%$ & 1.856 & 2.136 \\
\cline { 2 - 4 } & $2 \%$ & 1.909 & 2.189 \\
\cline { 2 - 4 } & $4 \%$ & 1.963 & 2.243 \\
\cline { 2 - 4 } & $6 \%$ & 1.994 & 2.274 \\
\hline \multirow{5}{*}{6000} & $0.5 \%$ & 1.834 & 2.113 \\
\cline { 2 - 4 } & $1 \%$ & 1.887 & 2.220 \\
\cline { 2 - 4 } & $2 \%$ & 1.941 & 2.274 \\
\cline { 2 - 4 } & $4 \%$ & 1.994 & \\
\cline { 2 - 4 } & $6 \%$ & 2.026 & \\
\hline
\end{tabular}

The results from tables 6,7 and 8 demonstrate that as long as the errors in estimating the ADTT and the percent of side-by-side events remain within a factor of 3 , the error in the expected maximum live load effect, $\mathrm{L}_{\max }$, will remain within $5 \%$ or less. 


\section{Discussion}

As observed from the sensitivity analysis, the projection of the maximum load effect for short to medium span bridges for two-year and 75-year projection periods is primarily controlled by three factors: 1) the number of events expected within the projection period, 2) the percentage of the loading events that are closely spaced and in particular those due to side-by-side trucks, 3) the trucks that fall within the tail end of the load effect histogram. The sensitivity analysis has demonstrated that a change in the number of events on the order of $+/-300 \%$ leads to minor errors in the estimated maximum load effect of about $+/-5 \%$. Similar results are observed for errors in the estimated percentage of side-by-side trucks. As shown, the most important parameters are those that describe the shape of the tail end of the histogram. In principle, the simplified analysis approach can handle any shape for the tail end of the load histogram assuming that the WIM data provide a full description of the tail. However, in reality it is impossible to obtain 75 year-worth of data to obtain a full description of the tail end of the histogram. Hence the method must rely on some assumptions and approximations to the tail end of the histogram. Therefore, extreme care must be taken during the WIM data collection process to ensure that the data is collected over long periods of time and is representative of the trucks with heaviest cargos.

\section{Accuracy of the proposed model}

In addition to the sensitivity analyses described earlier and the comparisons made for the different fitting techniques, the accuracy of the proposed model has also been compared with another simulation-based approach used by other researchers to estimate the maximum traffic load effect on highway bridges. A different WIM data set from that used in the previous analysis is also considered. The two models were applied on a set of WIM data collected in Slovenia (Znidaric et al. 2010) over a period of 58 days 
uninterruptedly. The total number of measured trucks was 147,752 and the average daily truck traffic (ADTT) was 3,293. Figure 6 shows the moment effect of the trucks that crossed the drive lane of a bridge with a span of 20 meters similar to the instrumented one (Casas, et al., 2012).The figure also shows the normal distribution fit to the tail end of the moment.

Table 9 compares the results obtained by various researchers for the maximum load effect for side-by-side trucks with the same WIM database for a simply supported 25-m bridge span. The researchers utilized the following approaches to project the load effects to obtain the maximum load in different service periods:

- Using the convolution of Eq. (2) with the original WIM data.

- Using the normal fit to the upper tail end of the original histogram as proposed here

- Large scale Monte Carlo simulation taking onto consideration, the weights of the trucks, the trucks' axle configurations, histograms of multiple presence and headway data as performed by Enright et al. (2010).

- A variation on the NCHRP method as performed by Znidaric (ARCHES D-08, 2009, Znidaric et al. 2012).

Table 9 demonstrates that all four approaches lead to very similar results with a difference less than $3 \%$ which verifies that the approach proposed here is most applicable for engineering practice because of its simplicity and ease of implementation. 
Table 9. Comparison of maximum load effect with different methods of analysis and different service periods (Slovenian traffic data)

\begin{tabular}{lllll}
\hline & WIM data & Znidaric & Normal fit & Enright \\
\hline 1 year & 4676.1 & 4698.7 & 4800.2 & - \\
5 years & 5053.8 & 5062.2 & 5117.0 & -- \\
50 years & 5510.5 & 5519.3 & 5530.1 & 5646.5 \\
75 years & 5586.9 & 5594.4 & 5598.7 & 5750.5 \\
\hline
\end{tabular}

The projection of the results to estimate the maximum load effect over the bridge's service period requires as input the number of events in the service period $\mathrm{N}$ in equations 4, 5 and 6. After many simulations and comparisons, Znidaric et al. (2012) proposed to use the time of arrival of trucks as registered in the WIM data file and count the number of events that the trucks fall within the middle $50 \%$ of the bridge's influence line to estimate the number of simultaneous crossings of trucks. The approach, which depends on the speed of trucks is illustrated in Figure 7. Table 10 gives the average number of two trucks simultaneously on the bridges expected for different span lengths and traffic speeds.

The analysis of the Slovenia WIM data for the maximum moment on different span lengths and different service periods is presented in Table 11. From table 11, it is seen that the maximum moment is obtained for the lowest speed, which produces the highest average number of two-truck events per day. This demonstrates that the side-by-side truck effect is the most critical for simple span bridges in the range of 20 to $50 \mathrm{~m}$. 


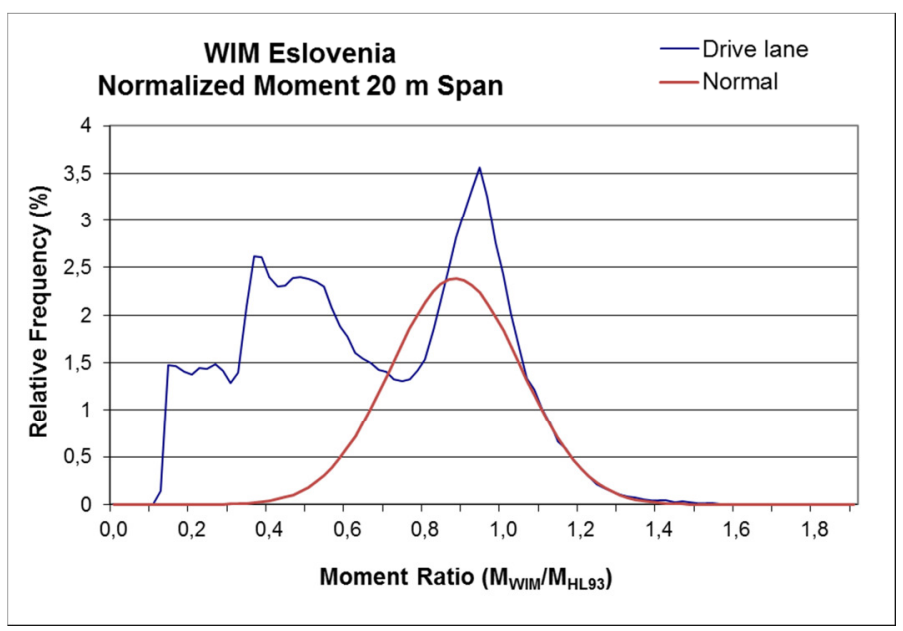

Figure 6. Moment effect of Slovenia traffic data on 20-m span bridge (drive lane)

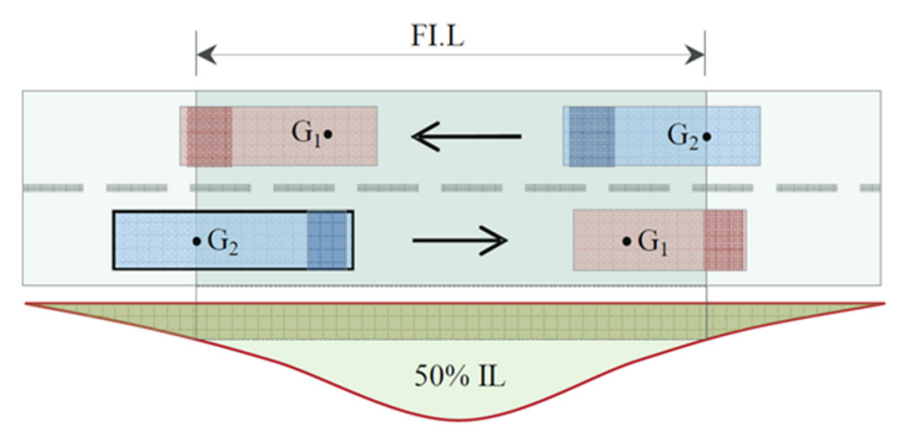

Figure 7. Modeling the number of simultaneous multiple crossings of trucks

Table 10. Average number of two-truck events per day.

\begin{tabular}{lllll}
\hline & $20 \mathrm{~m}$ & $30 \mathrm{~m}$ & $40 \mathrm{~m}$ & $50 \mathrm{~m}$ \\
\hline $80 \mathrm{~km} / \mathrm{hr}$ & 19 & 25 & 64 & 96 \\
$60 \mathrm{~km} / \mathrm{hr}$ & 23 & 64 & 101 & 148 \\
$40 \mathrm{~km} / \mathrm{hr}$ & 64 & 110 & 223 & 301 \\
\hline
\end{tabular}

\section{Applicability of the proposed model}

Table 12 gives the load effect for a 1000-year return period obtained from the analysis with the Slovenia WIM data for different span lengths. The 1000-yr is the return period recommended in the Eurocode for finding the characteristic value of traffic load effect. The values in Table 12 are obtained from the mean values in Table 11 assuming a coefficient of variation of the traffic action equal to $20 \%$. The higher COV used in this 
case when compared to those obtained from the projections of the load effect accounts for site to site variability as well as analysis uncertainties. The listed $1000-\mathrm{yr}$ values also include a 1.10 dynamic amplification factor (Ghosn and Moses, 1986).

Table 12 also lists the characteristic values according to Eurocode 1 for a bridge with a $9 \mathrm{~m}$ deck-width. The traffic load effects obtained from the real Slovenia WIM data are more than $20 \%$ lower than the ones recommended by the Eurocode of actions.

This result shows the usefulness of using WIM data for the evaluation of the effect of traffic loads on existing bridges using the proposed model in order to estimate the actual safety of the bridge by modeling the actual traffic loads rather than using the code specified values which may condemn a bridge that otherwise is actually safe.

Table 11. Maximum moment in $\mathrm{kNm}$ for different service lives and span lengths.

\begin{tabular}{|c|c|c|c|c|c|c|c|c|c|c|c|c|}
\hline & $20 \mathrm{~m}$ & & & $30 \mathrm{~m}$ & & & $40 \mathrm{~m}$ & & & $50 \mathrm{~m}$ & & \\
\hline & $80 \mathrm{~km} / \mathrm{h}$ & $\begin{array}{l}60 \\
\mathrm{~km} / \mathrm{h}\end{array}$ & $40 \mathrm{~km} / \mathrm{h}$ & $\begin{array}{l}80 \\
\mathrm{~km} / \mathrm{h}\end{array}$ & $\begin{array}{l}60 \\
\mathrm{~km} / \mathrm{h}\end{array}$ & $40 \mathrm{~km} / \mathrm{h}$ & $\begin{array}{l}80 \\
\mathrm{~km} / \mathrm{h}\end{array}$ & $\begin{array}{l}60 \\
\mathrm{~km} / \mathrm{h}\end{array}$ & $40 \mathrm{~km} / \mathrm{h}$ & $\begin{array}{l}80 \\
\mathrm{~km} / \mathrm{h}\end{array}$ & $\begin{array}{l}60 \\
\mathrm{~km} / \mathrm{h}\end{array}$ & $\begin{array}{l}40 \\
\mathrm{~km} / \mathrm{h}\end{array}$ \\
\hline 1 year & 3656.7 & 3680.8 & 3806.7 & 6291 & 6472 & 6571.2 & 9318.1 & 9433.2 & 9625.8 & 12025.6 & 12161.8 & 12378.6 \\
\hline 5 years & 3854 & 3876.6 & 3995.2 & 6590.7 & 6761.2 & 6854.9 & 9711.6 & 9820.3 & 10002.5 & 12515.8 & 12644.6 & 12849.8 \\
\hline 50 years & 4116.8 & 4137.7 & 4247.5 & 6990.3 & 7148.3 & 7235.3 & 10238.3 & 10339.3 & 10509 & 13172.8 & 13292.7 & 13484.1 \\
\hline 75 years & 4161 & 4181.7 & 4290.1 & 7075.6 & 7213.6 & 7299.6 & 10327.1 & 10426.9 & 10594.6 & 13283.8 & 13402.2 & 13591.5 \\
\hline
\end{tabular}

Table 12. Comparison of characteristic values of maximum bending moment at midspan from WIM data and Eurocode

\begin{tabular}{llll}
\hline Span $(\mathrm{m})$ & 1000 -year return value $(\mathrm{kNm})$ & Eurocode LM1 $(\mathrm{kNm})$ & Ratio \\
\hline 20 & 6414 & 8100 & 0.79 \\
30 & 10930 & 13725 & 0.80 \\
40 & 15875 & 20400 & 0.78 \\
50 & 20374 & 28125 & 0.72 \\
\hline
\end{tabular}




\section{Conclusions}

This paper reviewed the approach proposed by Ghosn and Sivakumar (2010) and NCHRP 12-76 (NCHRP 2011) for estimating the maximum truck load effect on bridges based on Weigh-In-Motion data. The paper demonstrates that the simple approach yields results very similar to those of more sophisticated models with a fraction of the required computational time and with much simpler input data requirements.

A parametric analysis shows that the approach, which is based on fitting the tail end of WIM data results with an equivalent normal distribution, is not very sensitive to errors in well calibrated WIM equipment. The method gives robust accurate results even when the WIM data is collected over short periods of time as long as the data collection period is carefully chosen to coincide with the crossing of representative truck traffic in terms of truck weight and volume.

The use of the proposed simple method, applicable to short to medium span bridges with span-lengths less than $50 \mathrm{~m}$, will help obtain improved assessments of the safety of existing bridges by providing realistic estimates of the applied live load effects when compared to the live load models recommended in codes and specifications oriented to bridge design.

\section{Acknowledgements}

The authors would like to thank the Spanish Ministries of Economy and Education for partially funding the study through Research Projects REHABCAR (INNPACTO) and BIA2010-16332 and Project SAB2009-0164 for supporting Prof. Ghosn's sabbatical leave at UPC. Thanks are also given to Mr. Ales Znidaric from ZAG for providing the Slovenia WIM data and his help in interpreting the traffic data and Mr. Bala Sivakumar 
from HNTB for providing and helping analyze the US WIM data. The financial support provided by NCHRP which sponsored some parts of the work presented in this manuscript is also acknowledged.

\section{References}

Ang, A. H. \& Tang, W. H., 2006. Probability concepts in Engineering Planning and Design. Wiley and Sons, New York.

ARCHES D-08, 2009. Recommendations on the use of results of monitoring on bridge safety assessment and maintenance. Deliverable D-08, ARCHES Project. VI EU Framework Program, Brussels ( http://arches.fehrl.org).

Caprani, C. , Grave, S. A., O’Brien, E., O’Connor, A., 2002. Critical Loading Events for the Assessment of Medium Span Bridges. in B. H. V. Topping and Z. Bittnar, eds. ICCST '02: Proceedings of the 6th International Conference on Computational Structures Technology, Prague, Czech Republic. Civil Comp Press.

Casas, J.R., 1999. Evaluation of existing concrete bridges in Spain. ACI Concrete International, 21(8): 48-53.

Casas, J.R., 2000. Safety of prestressed concrete bridges to fatigue: Application to Serviceability Limit State of decompression. ACI Structural Journal, 97(1): 68-74. Casas, J., Ghosn, M., Soriano, M., 2012. REHABCAR. Entregable 6.2.3. Guía para la definición de una prueba de carga tipo “proof”. Software, ábacos y tablas para la obtención de la prueba de carga. Madrid, Spain: Ministerio de Fomento, REHABCAR Project, INPACTO.

Casas, J.R., Gomez, J.D., 2013. Load Rating of Highway Bridges by proof-loading. Journal of Civil Engineering, Korean Society of Civil Engineers, 17(3): 556-567. 
Cohen, H., Fu, G., Dekelbab, W., Moses, F., 2003. Predicting Truck Load Spectra Under Weigh Limit Changes and its Application to Steel Bridge Fatigue Assessment. Journal of Bridge Engineering (ASCE), 8(5): 312-322

Crespo, C., Casas, J.R., 1997. A comprehensive traffic load model for bridge safety checking. Structural Safety, 19(4): 339-359

Crespo, C., CASAS, J.R, 1998. Fatigue Reliability Analysis of Prestressed Concrete Bridges. Journal of Structural Engineering (ASCE), 124(12): 1458-1466.

Enright, B., O’Brien, E., Dempsey, T., 2010. Extreme traffic loading in bridges. Proceedings of the Fifth International Conference on Bridge Maintenance, Safety and Management IABMAS2010, Philadelphia, USA.

Enright, B. , O'Brien, E., 2013. Monte Carlo Simulation of extreme traffic loading on short and medium span bridges, Structure and Infrastructure Engineering, 9 (12): 12671282

Fu, G., Tang, J., 1995. Risk-Based Prof.-Load Requirements for Bridge Evaluation.. Journal of Structural Enginnering, 121(3): 542-556.

Fu, G., You, J., 2011. Extrapolation for Future Maximum Load Statistics. Journal of Bridge Engineering, 16(4): 527-535.

Frangopol, D., Goble, G., Tan, N., 1992. Truck Loading Data for a Probabilistic Bridge Live Load Model. Proceedings of the Sixth ASCE Specialty Conference. Denver, Colorado, USA

Ghosn, M., Moses, F. , 1986. Reliability Calibration of Bridge Design Code. J. Struct. Eng., 112(4): 745-763

Ghosn, M., Moses, F., Gobieski, J., 1986. Evaluation of Steel Bridges Using In-Service Testing. Transportation Research Record, TRR 1072. 
Ghosn, M. , Frangopol, D., 1996., Site-Specific Live Load Models for Bridge Evaluation. Probabilistic Mechanics and Structural and Geotechnical Reliability, Proceedings of the 7th ASCE Specialty Conference, Worcester, MA, USA.

Ghosn, M., Sivakumar, B., 2010. Using Weigh-I-Motion Data for Modeling Maximum Live Load Effects on Highway Bridges. Proceedings of the Fifth International Conference on Bridge Maintenance, Safety and Management IABMAS2010, Philadelphia, USA

Ghosn, M., Sivakumar, B., Miao, F., 2013. Development of State-Specific Load and Resistance Factor Rating Method. J. Bridge Eng., 18(5): 351-361.

Gindy, M., Nassif, H., 2006. Multiple Presence Statistics for Bridge Live Load Based on Weigh-in-Motion Data. Transportation Research Board, 86th Annual Meeting, Washington, D.C.

Grundy, P. , Boully, G., 2004. Fatigue Design in the New Australian Bridge Design Code. Proceedings of the Austroads 5th Bridge Conference, Hobart, Tasmania.

Laman, J. A., Nowak, A.S., 1996. Fatigue-Load Models for Girder Bridges, Journal of Structural Engineering, 122(7): 726-733.

Laman, J. A., Nowak, A.S. 1997. Site-Specific Truck Loads on Bridges and Roads. Proceedings of the Institution of Civil Engineers: Transport, 123(2): 119-133.

Lu, Q., J. Harvey, T. Le, J. Lea, R. Quinley, D. Redo, and J. Avis, 2002. Truck Traffic Analysis Using Weigh-In-Motion (WIM) Data in California, Moses, F., Ghosn, M., Snyder, R.E., 1984. Application of Load Spectra to Bridge Rating. Transportation Research Record 950, pp. 45-53.

Moses, F., Schilling, C.G., Raju, K.S., 1987. NCHRP Report 299: Fatigue Evaluation Procedures for Steel Bridges, Transportation Research Board, Washington, D.C. 
Moses, F., 2001. NCHRP Report 454, Calibration of Load Factors for LRFR Bridge

Evaluation. Transportation Research Board, Washington, D.C.

NCHRP, 2011. Protocols for Collecting and Using Traffic Data in Bridge Design,

NCHRP Report $n^{\circ}$ 683. Transportation Research Board, Washington, D.C.

Nowak, A. S., Nassif,H., 1992. Live Load Models Based on WIM Data. Probabilistic

Mechanics and Structural and Geotechnical Reliability, Proceedings of the 6th ASCE

Specialty Conference, Denver, CO, USA.

Nowak, A.S., 1999. NCHRP Report 368, Calibration of LRFD Bridge Design Code.

Transportation Research Board, Washington, D.C.

O’Brien, E., Znidaric, A, 2001. Report of Work Package 1.2 - Bridge WIM Systems

(B-WIM). European project WAVE.

O’Brien, E., Schmidt, F., Hajializadeh, D., Zhou, X., Enright, B. Caprani, C., Wilson, S., Sheils, E., 2015. A review of probabilistic methods of assessment of load effects in bridges. Structural Safety, 53: 44-56

Treacy, M., Brühwiler, E., Caprani, C., 2014. Monitoring of traffic action locl effects in highway bridge deck slabs and the influence of measurement duration on extreme value estimates. Structure and Infrastructure Engineering, 10 (12): 1555-1572

Wang, T.-L., Liu,C., Huang, D., Shahawy, M., 2005. Truck Loading and Fatigue Damage Analysis for Girder Bridges Based on Weigh-in- Motion Data. Journal of Bridge Engineering, 10(1): 12-20.

Wisniewski, D., Casas, J.R., Ghosn, M., 2012. Codes for Safety Assessment of Existing Bridges-current state and further development. Structural Engineering International, 22(4): 552-561. 
Znidaric, A., Lavric, I., Kalin, J., 2010. Latest practical developments in the Bridge WIM Technology. Proceedings of the Fifth International Conference on Bridge Maintenance, Safety and Management IABMAS2010. Philadelphia, USA.

Znidaric, A., Kreslin, M., Lavric, I., Kalin, J., 2012. Simplified approach to modeling traffic loads on bridges. Transport Reseach Arena. Social and Behavioral Sciences, 48: 2887-2896. 